\title{
Evaluation of an integrated health and livelihood development program for marginalized communities in India
}

Shantanu Sharma ( $\sim$ shantanusharma145@gmail.com )

MAMTA Health Institute for Mother and Child

Faiyaz Akhtar

MAMTA Health Institute for Mother and Child

Rajesh Kumar Singh

MAMTA Health Institute for Mother and Child

Sunil Mehra

MAMTA Health Institute for Mother and Child

\section{Research}

Keywords: Adolescent, Community Participation, Employment, Health Education, Health Communication, Peer influence

Posted Date: January 9th, 2020

DOI: https://doi.org/10.21203/rs.2.20501/v1

License: (9) (i) This work is licensed under a Creative Commons Attribution 4.0 International License. Read Full License 


\section{Abstract}

Background Women from marginalized communities have poorer maternal health outcomes and limited utilization of health services compared to other communities. There is empirical evidence that comprehensively designed interventions targeting health education of women and social determinants of health, such as financial security, have better outcomes than focusing on health education alone. A community-based intervention was implemented to improve maternal, child, and adolescent health practices in marginalized communities. Besides, the project aimed to promote financial literacy and enhance livelihood opportunities for young people. This three-year peer-led intervention was done in the two districts of Rajasthan, namely Nagaur and Pali. The paper aimed at assessing the effectiveness of this community-based intervention.

Methods Pre-post study design based on qualitative research was used for the evaluation of the intervention. Purposive sampling was done both at baseline and the end-line assessments. Focus group discussions were done with women (15-49 years) and adolescents (10-19 years), and in-depth interviews with frontline workers and village health committees were done. Content analysis was done.

Results Overall, 4853 women, and 8158 adolescents were engaged in the intervention in two districts. We found a noticeable change in some of the practices like institutional delivery, breastfeeding, uptake of antenatal care among women, and knowledge about sexual and reproductive health among adolescents. Around $23 \%$ and $67 \%$ of the young people from Nagaur and Pali, respectively, were linked with jobs in computer training centers, tailoring centers, and beauty parlors. However, we found a lack of change in some of the indicators, such as knowledge about HIV testing during pregnancy, uptake of contraceptives, and iron-folic acid consumption among women. Early marriage was widely prevalent in the districts, the reduction of which was underachieved. In the interviews, frontline workers reported having been impartial and inclusive in delivering health services.

Conclusions We found evidence suggesting that peer-led interventions are equally effective in improving maternal and child health practices and livelihood promotion. The gaps at system-level, coupled with the presence of specific socio-cultural contextual factors might explain for lack of improvement in some of the indicators.

\section{Background}

India is ranked 115 out of 162 countries in the global ranking based on the achievements of Sustainable Development Goals (SDG) with an index score of 61.1. The country has major challenges remaining in the transformations to achieve SDG-3 of good health and well-being [1]. Despite India's groundbreaking success in reducing maternal mortality by $77 \%$ in 26 years, the change has not been equitable and remarkable across all geographies and communities [2, 3]. States with the highest burden of maternal mortality, such as Uttar Pradesh and Rajasthan, have the worst overall performance in health development [3]. Besides, women from marginalized communities have the worst maternal health outcomes. For example, the rate of skilled birth attendance differs by 31 percentage points between the richest and poorest women and by 15 percentage points between women from marginalized and non-marginalized communities [4]. Poor women from rural and remote areas and marginalized communities have limited access to maternal health care services, including antenatal care, skilled birth attendance, and postnatal care due to various socio-cultural and geographical barriers [5]. Hence, there is a need to improve access to and utilization of maternal and child health care services for women, particularly from marginalized communities.

Increasingly, community-based interventions have been recognized as an important component of comprehensively-designed maternal health programs [6]. However, recent systematic reviews have demonstrated that community-based interventions dependent on the health education of women alone may not be successful in improving the utilization of maternal and child health care services. Instead, community-based programs integrated with multiple interventions greatly improved maternal health outcomes $[7,8]$. There is emerging evidence on the impact of fostering financial security and social inclusion in reducing inequities for access to maternal health care $[9,10]$. Ensuring livelihood can bring financial security and access to financial services to vulnerable people. However, there are limited livelihood opportunities for young people in India due to a lack of skills, education, and a huge competition [11]. Gender inequality and rural-urban differences in access to job 
opportunities further add to the growing problem of unemployment and livelihood struggles for the marginalized populations [12].

A number of agencies, including governmental and non-governmental, have been working towards strengthening the skills of young people, besides improving the health status of marginalized populations, but scientific evaluation of such interventions is limited. Given the scant evidence of the effectiveness of community-based interventions in improving the utilization of health services among women along with skill development programs for young people, we designed a peer-led program. We delivered a three-year intervention in the two districts of Rajasthan, a state situated in Western India. The paper aimed at assessing the effectiveness of this community-based intervention in improving maternal and child health outcomes through integrating livelihood generation and health education components.

\section{Description of the community-based intervention}

\section{Objectives of the intervention}

The intervention was designed to enhance demand generation for maternal and child health services and strengthen the financial literacy of young people and linking them with employment services. The specific objectives of the project were: a) to improve maternal, child, and adolescent health practices in the communities through a life course approach; $b$ ) to create an enabling environment for enhancing accessibility and utilization of health services among women; c) to promote financial literacy and linkages for improving livelihood opportunities among marginalized communities. The marginalized communities included population belonging to scheduled castes, scheduled tribes, other backward classes, or those living below the poverty line. The key strategies of the intervention included the health education of women and adolescents through structured sessions, modular training of young people on financial literacy and livelihood promotion, and one-to-one interactions with stakeholders for influencing the uptake of maternal and child health services. The logic model of the intervention with objectives, strategies, and their links to outputs is provided in Table 1.

\section{Intervention settings}

The project was implemented in two districts of Rajasthan, namely Nagaur and Pali. Rajasthan, a state in Western India, has a population of 60 million, a child sex ratio of 888 , a female literacy rate of $52 \%$, and maternal mortality ratio of 182 per $1,00,000$ live births $[13,14]$. All the 32 districts of Rajasthan were ranked based on gender-related development index, which is a composite index of health, education, and income indicators [15]. The districts were further grouped into three categories as the highest one-third, middle one-third, and the lowest one-third groups. Two districts (Nagaur and Pali) were randomly selected from the lowest one-third group. One block was selected randomly from each of the two districts. The intervention was done in 28 and 29 villages in Nagaur and Pali, respectively. Both districts had poor maternal and child health indicators (Supplementary Table 1).

Furthermore, the intervention population (married women in the reproductive age group (15-49 years) and unmarried adolescents) was selected after community mapping and line-listing. We had a mixed team of 20 men and women, which included public health specialist $(n=1)$, district coordinators $(n=2)$, outreach staff $(n=10)$, and monitoring and evaluation officer $(n=1)$. District coordinators and outreach workers belonged to the intervention area and were well versed in the local language and cultural practices. The roles of each of these implementing actors are given in Figure 1.

\section{Intervention activities}

The cascade model of training was adopted. A standard training of 4 days at the beginning of the project and two days (refresher training) each at three times during the entire duration of the project was conducted for outreach staff by the public health specialist. The training of outreach staff was done on various issues of maternal, newborn, child health and nutrition, and adolescent sexual reproductive health and rights. The outreach staff identified women and adolescents in the communities and groups of 20-25 women and adolescents were formed. In every group, one leader was selected, who was named as a peer leader. The outreach staff conducted 6-day training of the peer leaders in the villages on similar content.

Page 3/18 
These peer leaders had the responsibility to educate other women or adolescents on maternal, child, and adolescent health and nutrition issues in the villages. There were 540 peer leaders from the women's group. The socio-demographic details of the adolescent peer leaders are provided in Table 2. Peer leaders were provided small cash-based incentives to manage sessions, call participants for attending sessions, and use transport to reach the dropouts at their houses.

The health education program for women had 10-structured sessions distributed over ten months. The titles of the ten sessions were pre-pregnancy care, safe motherhood, intra- and post-partum care, and prevention of parent to child transmission of HIV, prevention of malaria during pregnancy, newborn care, breastfeeding, and immunization, care during post-neonatal period and prevention of undernutrition among children. Similarly, six-structured sessions were conducted with adolescents. The names of these six-sessions were understanding adolescence, understanding gender and sex, adolescent's rights, contraceptives, stress and emotions management, and prevention of anemia. The sessions with the women were conducted in the villages at a suitable place (health center, Anganwadi center, or community hall). Anganwadi centers are the child development centers in the villages where women, adolescent girls, and children are provided supplementary nutrition, health education, and nutrition-related services [16]. Each session lasted for 1.5-2 hours, beginning with the rounds of introduction, followed by the main content of the session, questions and answers, and lastly, a short story to convey the message of the session.

Besides, youth information centers were created in the villages. The youth information centers served as resource centers of infotainment, recreational activities such as indoor games, group discussions, and safe spaces for girls. In total, five youth information centers were created in Nagaur and 4 in Pali. The stakeholders who had an impact on the health practices of women and adolescents such as husbands, mothers-in-law, and parents were engaged. This facilitated the creation of an enabling environment for the change to happen. The engagements were done through community events and mass meetings. A single one-day orientation workshop for frontline workers was conducted in each of the two blocks. Three major issues covered in the workshop were the prevention and management of anemia and nutritional problems among women and adolescents, breastfeeding promotion, and family planning. Single one-day orientation workshop for medical officers was organized in each of the two blocks to discuss the major health-, nutrition- and sanitation-related emerging issues from the communities. In addition, meetings were held with the heads and members of the Village Health Sanitation and Nutrition Committees (VHSNC). VHSNC are health committees serving as vehicles for community health governance. Their key strategies include providing an institutional mechanism for the community to voice its needs, share experiences and issues regarding access to health services. In addition, they provide support to frontline workers, facilitate service delivery at facilities, and village health planning [17].

The young people were trained on financial literacy and livelihood promotion program through a three-day training workshop in both districts. The key issues discussed during the workshop included qualities of starting a business, business preface, requirements to establish an enterprise, business communication skills, preface of business conflicts, registration processes, principles of management and accounting, the opening of bank accounts, fund management, government schemes, marketing management, and non-financial assistance. An external agency facilitated the training. In addition, we sought support from the state development livelihood corporation and micro small and medium enterprises.

The implementation of the intervention began in 2014 for three years. A baseline assessment survey preceded the intervention. An excel-based management information system was established, which was updated by the staff monthly. We collected the socio-demographic details of the beneficiaries (women and adolescents) who enrolled in the program. The field visits and review meetings were done quarterly, and discussions were done to address the field-level challenges.

\section{Methods}

\subsection{Study setting}


Pre-post study design based on qualitative research was used for the evaluation of the intervention. No control group was present. The qualitative interviews at the end of the program were conducted by researchers not associated with the intervention. It took an average of 2 months at the beginning and end of the intervention to conduct all the interviews. The baseline assessment was done in July and August 2014, and the end-line assessment was done in February and March 2017. The intervention was delivered over a 30-months period from 2014 to 2017 . The evaluation was done at the same sites as the intervention.

\subsection{Study methodology}

The objective of the baseline qualitative assessment was to do the situational analysis of the knowledge and practices related to reproductive health among adolescents and livelihood opportunities in the communities. In addition, we wanted to understand the awareness and utilization of maternal, child health, and nutrition services by women. In total, 12 in-depth interviews (IDI) with frontline workers, four focus group discussions (FGD) with women, 4 FGD with adolescent boys and girls (two each), and 2 FGD with members of VHSNC were conducted at the baseline.

A similar pattern and an equal number of interviews were conducted at the end-line assessment. The end-line evaluation was done to assess change in the perception of the adolescents, women, frontline workers, and VHSNC members on the issues of health, nutrition, life skills, and livelihood opportunities. Around 10-12 people participated in every FGD. Each FGD lasted for 60-80 minutes, beginning with the introduction, explanation on the objective of the assessment, and discussion on the key issues of the assessment.

Purposive sampling was done both at baseline and the end-line assessments. At the baseline, the inclusion criteria for frontline workers and VHSNC members were working in the communities under the study for the past one year. The inclusion criteria for FGD with women and adolescents were living in the area for the past one year. Similarly, at the end-line, focus groups were done with women and adolescents, who were in the same area of the study and were associated with the intervention for at least one year. The frontline workers at the facilities were included in the study if they were associated with the intervention for at least one year and participated in the events or meetings organized during the project. The interviews or discussions were done at a suitable place in villages. Interviews at the baseline were conducted by two resource persons, who later became a part of the project. However, at the end line, the interviews were conducted by an external researcher in both districts (not associated with the project). In the end line, the external researcher was assisted by the staff of the project in facilitating the meetings and managing audio recordings.

\subsection{Study tool}

Baseline: The semi-structured qualitative questionnaire contained questions on perceptions of women related to the utilization of antenatal care, nutritional services, institutional delivery, postnatal care, newborn care, and family planning methods.

Besides, we assessed the perception of women related to knowledge about HIV/AIDS and its testing. The questionnaire for adolescents assessed perception related to schooling, social interaction, early marriage, health service utilization, life skills, and livelihood opportunities. Frontline workers were asked about their perceptions related to service utilization among marginalized communities, their attitude towards inclusive service delivery, and job opportunities for young people in the communities.

End line: A structured, deductive qualitative interviews explored the perceived change in the knowledge, and practices of women and adolescents related to health, nutrition, and livelihood opportunities at the end line. Similarly, frontline workers and VHSNC members were interviewed about the perceived changes in the utilization of maternal and child health services by women and livelihood opportunities for young people. Participants were asked open-ended questions exploring how did the intervention help them in bringing change in their lives and what were the critical factors for the success of the intervention.

\subsection{Data synthesis}

All the interviews were recorded in Dictaphone, which were transcribed and written later. The transcripts were written in English by the researchers. The transcriptions were evaluated and consistency in the information obtained was cross-checked. A 
qualitative matrix was developed a priori on the themes based on the objectives of the assessments.

\subsection{Ethical clearance}

Ethics approval for the study was obtained from the MAMTA Institutional Ethical Review Board. Verbal informed consent was obtained from all the participants. In the case of adolescents, consents were also obtained from their parents. All the participants were ensured of the confidentiality of the information shared with the project staff and research teams. The records of the interviews were destroyed after the study.

\section{Results}

Overall, 4853 women and 8158 adolescents were engaged in the intervention. Of the total, $68.2 \%$ of the women and $52.0 \%$ of adolescents were from Nagaur, and $31.8 \%$ of the women and $48.0 \%$ of adolescents were from Pali. The socio-demographic details of women and adolescents have been shown in Tables 3 and 4, respectively. Approximately $8 \%$ of the women had married before the age of 18 years. The majority of the population in the two areas were Hindus (96.4\%). Around $86-87 \%$ of the adolescents and $85-87 \%$ of the women belonged to marginalized populations. More than two-thirds of the women who were enrolled in the intervention attended any education session in both districts. Sixty-nine percent and $62.5 \%$ of adolescents from Nagaur and Pali, respectively registered in the intervention ever attended an education session.

\subsection{Qualitative assessment at baseline}

The qualitative data at the baseline assessment has been divided into three main themes.

\subsubsection{Perceptions on the utilization of maternal and child healthcare services by women}

Women were aware of the antenatal care visits, the importance of taking a nutritious diet during pregnancy, and danger signs during pregnancy, such as fever, abdominal pains, and bleeding. Despite knowing the need to increase the dietary intake during pregnancy, only a few of them could add extra calories in the diet through nutritious foods. A lot of these women did not consume supplementary food supplied at Anganwadi centers because of its low quality. Women told that the government scheme of cash incentives for institutional delivery had promoted the uptake of antenatal care. However, most women did not visit the health facility within the first trimester. The socio-cultural norms and superstitious thoughts prevented women from disclosing their pregnancy status within the first three months.

If we visit a health facility within the first trimester, people will come to know. And evil's eye will be on us. This will hamper the growth of our child. We do not want this.

Women regularly went for antenatal check-ups and other blood or urine tests. However, the consumption of iron-folic tablets was not common. The most common reason for not consuming iron-folic acid tablets was its side effects. Some of the women reported problems in accessing health facilities. Long distances to health facilities, lack of adequate staff, and lady doctors at primary health centers, an insensitive attitude of the frontline workers, and unhygienic surroundings were commonly reported problems in accessing health facilities. The uptake of postnatal care visits was low, and in fact, many did not know about it. Exclusive breastfeeding was a norm in the society, and early breastfeeding was common among women who were delivered in the institutions.

Most of the women knew about the family planning methods and ill effects of big families. However, the use of contraceptives was not common among newly married women. Most of these women had pressures from their families to give birth to a child soon after marriage.

We know about family planning methods. We know the slogan also. We two, ours two.

3.1.2. Perceptions of the adolescents about schooling, health and livelihood needs 
School drop-outs were common among boys and girls. The reasons for drop-out among boys were pressure from the families to earn and contribute to the income of the family and lack of good quality teachers in schools. On the contrary, long distances to secondary schools, poverty, safety or security, and early marriages were the common reasons for the drop-out of girls. As a result of lower education, both boys and girls had limited opportunities for employment. Early marriage was common in both districts. Traditional customs, social pressures, and parents' over dominance were reported as the reasons for early marriage in the areas.

An old custom of selling and auctioning their daughters is still common in some of the communities of Nagaur.

Poor sanitation and water-borne illnesses were common in the areas. Many adolescents were unaware of sexually transmitted diseases and HIV/AIDS. Girls often referred to their elder sisters for their reproductive health problems while boys did not share their reproductive health problems with anyone. Alcohol drinking, smoking, and tobacco chewing were common among boys and, to some extent, among girls. Adolescents lacked confidence, communication skills, and opportunities for skills training. Handyman jobs such as mobile repairing, electric appliances repairing, decoration, tenting, etc. were common among young people in the districts. Beautician and tailoring were preferred jobs among girls.

3.1.3. Perceptions of frontline workers on the utilization of services by women, inclusive service delivery in facilities and livelihood opportunities for young people

Anemia and low uptake of family planning methods among women were common problems in the areas. Frontline workers told that no discrimination was done based on castes while delivering maternal and child health services. Pregnant women visited Anganwadi centers regularly. Women from upper socioeconomic status preferred to deliver at home in the presence of skilled birth attendants while others preferred to deliver in institutions. Pregnant women underwent HIV/AIDS testing.

Approximately one in three women had sexually transmitted infections. In addition, women used pills and copper T as family planning methods. Frontline workers told that consumption of iron-folic acid tablets was poor among adolescent girls.

Frontline workers reported that the participation of women in livelihood schemes was more than men. The migration of the youth to the urban areas was common due to a lack of job opportunities in the intervention sites.

\subsection{Qualitative data from the end line evaluation}

3.2.1 Perception of women on the change in maternal and child healthcare knowledge and practices

Pregnant and lactating mothers told that a woman should marry when she is at least 20 years old and should undergo pregnancy at least 2-4 years after marriage. They were aware of the importance of pregnancy care.

A woman should have a child four years after marriage. A woman is weak in the early years of life and would give birth to a weak child. She should enjoy her married life before getting pregnant and understand her relations.

According to them, nutritious food is the major factor that keeps a pregnant woman healthy. There was a high production of milk and milk products in their villages, which they thought were nutritious and would keep them healthy. Women relied on mothers-in-law and Anganwadi workers in their villages for maternity care. Bleeding, abdominal pain and high fever were reported as the most common danger signs during pregnancy. Most of the women were aware of the antenatal check-ups, immunization of child, anemia, iron-folic acid consumption, and blood tests during pregnancy. However, barriers in accessing health services persisted, such as long distances to the facility from villages, lack of enough medical staff, and disrespectful attitude of the health center staff. Despite these barriers, many women had delivered in a health facility.

We should get abdominal ultrasonography done, take medicines and vaccines, blood tests, registration at Anganwadi center, and receive nutritional counselling. We need to get our children immunized to protect them against disability and illnesses. We need to consume iron-folic acid tablets because of anemia. We did not face any problem while taking iron-folic acid tablets. 
There are problems such as midwives are not available at the centers. They come for delivery mainly, and the sub-center is quite far from our village. In case we fall sick or develop complications, we had to travel a long distance to access services. Moreover, it's difficult to call an ambulance or any other transport because of a lack of good roads. (A woman during FGD)

We tend to arrange our vehicle for transport to the hospital for delivery, or we hire a taxi. We had even rented a vehicle for this purpose. We had to pay rupees 2000-4000 for the vehicle, but it is ok. We had to face more problems if we deliver at home.

Most of the women told that they knew about the sources of nutritious food, but could not afford to prepare them. Most of the women worked in fields and earned around INR 300 per day. Women knew about exclusive breastfeeding practice and its importance.

We need to give the yellow milk that comes out initially to our child and breastfeed them until six months of age. But we need to give 'ghutti' (a combination of Ayurvedic medicines) at the time of birth to the child. It's a tradition in our villages, and we could not avoid it.

Most of the women had heard about family planning methods. They were aware of the side effects of multiple pregnancies and a big family. They recited a slogan, 'We two, ours two' in the local language (Hindi). However, they told that the use of contraception among newly married couples was low. Their attitude towards the use of contraceptives was not positive.

We were totally unaware of the family planning methods earlier. However, in the meetings organized by the MAMTA organization, we were told about them.

We know about Copper T, sterilization, etc. We are also given condoms by midwives for husbands. But our husbands don't use them. Why should we take condoms from health workers if we have to undergo sterilization? After sterilization, we had complaints of lower backache and weakness. We had to do a lot of household work, including chopping grasses in the fields. If we fall sick, how will the work at home be managed?

We found that women had little or no information about HIV/AIDS or sexually transmitted infections. Many women were referred for HIV testing during pregnancy, but they were unaware of the reasons for the testing. Women received postnatal care visits to frontline workers and increased their diets during pregnancy.

\subsubsection{Perceptions of adolescents on the change in the knowledge and practices related to health and nutrition}

Adolescents knew that education is important, and they need to complete their schooling. Boys were employed as labor at construction sites on daily wages.

Boys drop out of school and search for jobs. They find jobs at construction sites and are paid up to Rs. 700 daily.

Many adolescents did not report that they visited youth centers during their leisure time. Early marriage was reported in the interviews. Mostly girls were married off early before the legal age of marriage. The common reasons of early marriage cited were traditional beliefs, societal pressure, and parent's wish.

The age of marriage should be 24 for boys and 22 for girls, at least. By this age, boys and girls are mature and they know how to run a family. And before this age, girls should study. Child marriage is wrong. Girls are not mature before the age of 18 years, and it's difficult for them to handle themselves, their families, and child. Big responsibilities at an early age are not good.

It was perceived that both boys and girls had a very comprehensive knowledge of sexual and reproductive health rights. They were able to explain what are the typical bodily changes and growth among boys and girls. Adolescents reported that they had been benefited by coming to the meetings organized during the project. Talking about sex education was considered taboo, and most of the people were hesitant in talking about it openly. However, boys and girls considered that men should be 
equally responsible for household work. They told that girls should also be given an opportunity to study, work, and drive. Adolescents were aware of contraceptives, such as condoms and pills.

We had benefited from the meetings. Nobody made fun or cracked jokes in the meetings. We were hesitant and afraid to discuss reproductive issues in the beginning. But later, we could discuss issues openly; such as menstruation, night falls, AIDS.

When I first had periods, I cried and was anxious. My mother helped me in using pads. If the period doesn't come on time, we are even more worried. Periods are delayed if you are sick or have anemia. Parents asked us to avoid eating sour and cold foods during periods. Sometimes, we feel bad and think it would have been really nice if we were born as boys and not girls. Periods are a bit frustrating.

Adolescents were aware of the ill effects of alcoholism and drugs on health and family.

Boys often get addicted to drugs. Friends put pressure to start drinking. But it is bad. Excessive drinking weakens the body. Binge drinkers could not understand the needs of their families and become incapable of handling their families. Such drinkers often beat their wives, and the whole environment of the family gets disturbed. Their liver gets damaged, and the mind is equally affected.

Adolescents wanted to switch to newer job opportunities such as teaching, computer work from conventional jobs such as construction workers, daily wage labor, etc. However, lack of life skills, confidence, and opportunities often prevented them from fulfilling their dreams.

3.2.3 Perceived changes according to frontline workers and VHSNC members in the livelihood opportunities and service utilization by women and adolescents

There were limited job opportunities for young people in the intervention areas. Frontline workers reported that they did not practice discrimination between marginalized and non-marginalized populations. Frontline workers told that they provided antenatal and postnatal care, counselling on breastfeeding, immunization, and complementary feeding to all women coming to the health facilities.

We tried our best to reach the unreached population; however, there were certain castes that did not approach for services.

We keep a woman for three days post-delivery in the hospital. After that, we do home visits 7 times.

People were still hesitant to discuss HIV/AIDS openly. Commonly, family planning methods were adopted by females and not males.

Mainly females undergo sterilization or other methods of contraception. We are told by women while counselling for family planning that since males have to go for work, it would be difficult for them to go for work if they fell sick due to sterilization.

According to the members of VHSNC, the facilities in schools for education had increased. The enrollment of girls has increased, and drop-out had decreased in schools.

Nobody marries before the age of 25 nowadays. Most of the children complete education until the $10^{\text {th }}$ standard, but we have been trying to make it up to $12^{\text {th }}$ for all. Children from marginalized families mostly study in government schools. We award the meritorious students with cycles. There are two government and private schools in our area. My two daughters also study in schools. They are in $10^{\text {th }}$ and $12^{\text {th }}$ standard.

VHSNC members reported that child marriage had dropped in the area due to strict action by the police. Youth information centers were effective in transferring health-related knowledge among young people. 
If we come across any news about the child marriage, we inform the police and stop it. MAMTA has helped us in guiding and promoting action against child marriage. We have to keep motivating people not to marry their children before the age of 18 years. Illiterate parents are often interested in child marriage.

\subsubsection{Financial literacy and livelihood promotion training program}

Nagaur: Of the total 210 young people who attended the training, 171 were in the age group of 16-19 years, and 39 were in the age group of $19-25$ years. Hundred and sixteen (55\%) out of the total 210 were girls, and 94 were boys (45\%). Around $23 \%$ of the young people were linked with employment. Young people were linked with jobs in the computer training center, tailoring center, and beauty parlor.

Pali: Of the total 164 young people who attended the training, 123 were in the age group of $16-19$ years, and 40 were in the age group of $19-25$ years. Eighty-nine (54.6\%) out of the total 163 were girls, and 74 were boys (45.4\%). Around $61 \%$ of the young people were linked with employment. Young people were linked with jobs in the computer training center, tailoring center, photography, and beauty parlor.

\section{Discussion}

The findings indicate that this peer-led intervention has shown an improvement in maternal, child, and adolescent health and nutrition practices and livelihood opportunities among marginalized populations in India. A noticeable change was reported in some of the practices like institutional delivery, breastfeeding, uptake of antenatal care among women, and knowledge about sexual and reproductive health among adolescents. These results are consistent with the existing evidence on communitybased interventions for improving health practices among marginalized populations in India [18-22]. However, a lack of change in some of the indicators, such as knowledge about HIV testing during pregnancy, uptake of contraceptives, and ironfolic acid consumption among women was evident in the interviews. Hesitancy in the communities to talk about HIV/AIDS was the prime reason for its low awareness level. This is supported by the fact that less than one-third of the people in Rajasthan had comprehensive knowledge about HIV/AIDS, which is further lower among marginalized populations [4]. It is difficult to interpret that the change in iron-folic tablets' consumption and contraceptive uptake did not happen because of a lack of intervention rigor or activities. Recent evidence from other community-based programs suggests that the changes in indicators like iron-folic tablets consumption or uptake of contraceptives were difficult to achieve only by behavioral interventions. Other factors, such as gaps in supply-chain, socio-demographic determinants, and cultural practices, have a crucial role to play $[19,22]$. This creates a need to develop a comprehensive intervention approach for targeting these indicators among women and addressing both individual- and system-level factors.

We have not been able to achieve success in reducing early marriage rates to a large extent. Rajasthan is one of the states in India with the highest proportion of early marriage rates. Not only does early marriage lead to early pregnancy, early childbirth, increased maternal and child mortality, but is also related to other social problems, such as intimate partner violence, big family size, poverty, etc. [23]. UNICEF proposed five key approaches to end child marriage and empower adolescents, which are supporting adolescents as agents of change, social mobilization among parents and communities, investing in the education of parents, access to social protection schemes, and linkage with skills and employment opportunities [23]. We endorsed three of the five key approaches in our intervention. Limited intervention coverage, and target population, and short duration of the program might be the plausible explanation for the poor achievement of decline in early marriage rates.

It was found that young people, because of a lack of skills and employment opportunities in the villages had to do semiskilled jobs like handyman work. Most of the people were interested in enhancing their skills and exploring jobs that require higher skills and are paid a higher salary. We had organized skills-building workshops for a limited number of people. However, around $42 \%$ of the young people who participated in the livelihood training were linked with jobs in our intervention. The results from this study can be used as evidence to create more job opportunities in villages, and the administration can organize skills-building workshops. Recently, the government of India launched a program, Prime Minister Skill Development (PMSD) program, to encourage and promote Skill Development for the youth throughout the country. Reports estimate that 
over 7000 young people in Nagaur and Pali have been trained on various vocational courses under the PMSD program [24]. The placement rate was $52 \%$ for the state under the scheme. Besides, other not-for-profit agencies have been working in the state towards building skills and providing job opportunities to young people. However, some of the major challenges in the PMSD program reported were the training was done on skills, which were not needed in the job where they were placed, training was not aligned with the job demands, and the high cost of the courses [25]. It has been reported that out of the total placements done in the PMSD program, $52 \%$ of them were occupied by females and $48 \%$ males by males, which reflects positive change towards women empowerment. Further, future intervention research may be warranted to assess the gender disparities in accessing livelihood opportunities in villages.

In the interviews, frontline workers reported having been impartial and inclusive in delivering health services. Discrimination against marginalized populations in delivering health services was not observed during the intervention. Although some of the women reported insensitive attitudes or behavior of frontline workers towards them, that was not based on their castes or religion. There is emerging evidence on the mistreatment or disrespectful maternity care by frontline workers in the health facility to women during antenatal and postnatal care. The prime drivers for mistreatment by frontline workers include resource-constraints, shortages of health workers, lack of adequate knowledge, and imbalanced power dynamics between health workers and pregnant women [26]. The government of India had recently launched guidelines for midwifery services, which emphasizes respectful maternity care. We focused on an inclusive service delivery approach in our meetings for frontline workers, but the component of respectful maternity care was not addressed.

There is empirical evidence on the effectiveness of peer education as a useful strategy to target health outcomes, especially knowledge across several populations $[27,28,29]$. Our program was based on the peer-led approach with concurrent involvement of other stakeholders who influence the behavior of women and adolescents. The sociodemographic profile of the peer leaders is one of the key factors that determine the successful implementation of peer-led health promotion programs [27]. In our study, we took peer leaders of a similar age, social class, and sex for better acceptability and responsiveness of the participants. Bringing peer leaders from the same community and repeated skill development of peer leaders proved beneficial for the effective delivery of the intervention.

The average size of a peer-led group was 20-25 in our sessions, which has been argued in other studies to be ineffective [27]. However, repeated dosing of key messages, interactive discussions, and case story-based learning during sessions helped in overcoming the problem of having large groups. Besides, reinforcing health promotion messages through community events also helped. Incentivizing peer leaders had helped us in ensuring the follow-up of participants and their adherence to the sessions. There is documented evidence that says the use of incentives may motivate peer leaders to get involved and stay engaged in the program over time [27]. Many studies conclude that longer exposure is required for sustained behavior change [28]. In our study, the health education content was distributed in 6-10 structured sessions for beneficiaries. The opportunities to interact with the beneficiaries repeatedly over 6-10 sessions were perceived effective for the intervention.

Limitations

The results should be interpreted considering the following limitations. Firstly, the intervention was limited to two districts in a state with a high burden of maternal mortality and poor health status of the populations. Besides, these two districts lie at the heart of the desert and are arid with livelihood limited to agriculture and livestock. These districts witness extensive migration, and have extremely orthodox societies, with rigid and rather unequally defined caste and gender relations [30]. Secondly, the evaluation of the intervention was based on the qualitative methodology; as a result, we could not quantify the change. The study lacks measurement of the correlations between access to livelihood and change in health outcomes. Dose-response analysis could not be performed due to a lack of quantitative measurement of the outcomes. Lastly, the intervention was limited to the communities without aggressive engagement with the system. This might have led to a poor or insignificant improvement in some of the indicators. Hence, the results cannot be generalized to the rest of the state or country.

\section{Conclusions}

Page 11/18 
This intervention contributes to evidence generation of peer-led approach in bringing change towards health and nutrition practices of marginalized women and adolescents. In addition, strengthening skills and livelihood generation for young people were also a part of the intervention. The intervention was successful in improving many health and nutrition practices, except for iron-folic tablets' consumption, contraceptive uptake, and reduction in early marriage rates. This calls for a comprehensive and multi-dimension intervention that targets social determinants of health and works aggressively with the systems.

\section{List Of Abbreviations}

AIDS: Acquired Immunodeficiency Syndrome

HIV: Human Immunodeficiency Virus

INR: Indian Rupees

IDI: In-Depth Interviews

PMSD: Prime Minister Skill Development

FGD: Focus Group Discussions

SDG: Sustainable Development Goals

VHSNC: Village Health Sanitation and Nutrition Committees

\section{Declarations}

\section{Ethics approval and consent to participate}

The study design, consent forms, and data collection tools were approved by the MAMTA Institutional Ethical Review Board (MERB). Verbal informed consents were obtained from the individuals above 18 years of age and parents of the individuals less than 18 years of age.

\section{Consent for publication}

The research team explained all the interviewees about the project and the research. We assured people of the privacy of their data.

\section{Competing interests}

The authors declare that there are no competing interests.

\section{Availability of data and materials}

The reports and related documents of the project can be made available on request over email to the corresponding author.

\section{Funding}

The project was a part of the corporate social responsibility by Greenlam company.

\section{Authors' contributions}

FA and SM conceived the intervention design and evaluation protocol. RKS managed data collection, entry, and analysis. SS performed a thematic analysis and wrote the manuscript. All authors reviewed and approved of the final manuscript. 


\section{Acknowledgements}

We acknowledge and thank Shilpa, Saket Raj, and the field teams for their contributions to project management and intervention activities. We acknowledge Sanjay Chaubey for his contributions to data management in the management information system. We acknowledge and thank the communities and peer leaders for their support and continuous engagement throughout the project.

\section{References}

1. Sachs J, Schmidt-Traub G, Kroll C, Lafortune G, Fuller G. Sustainable Development Report 2019. https://github.com/sdsna/2019GlobalIndex/blob/master/country_profiles/India_SDR_2019.pdf. Accessed 5 Oct 2019.

2. World Health Organization. India has achieved groundbreaking success in reducing maternal mortality. 2018. https://www.who.int/southeastasia/news/detail/10-06-2018-india-has-achieved-groundbreaking-success-in-reducingmaternal-mortality. Accessed 12 Dec 2019.

3. World Bank, Government of India, and NITI Ayog. Healthy states, Progressive India. Reports on the rank of States and Union Territories. 2018. https://niti.gov.in/writereaddata/files/Healthy-States-Progressive-India-Report.pdf. Accessed 15 Aug 2019.

4. International Institute for Population Sciences (IIPS) and ICF. National Family Health Survey (NFHS-4), 2015-16. 2017. http://rchiips.org/nfhs/NFHS-4Reports/India.pdf. Accessed 10 Jun 2019.

5. Jacobs C, Michelo C, Moshabela M. Implementation of a community-based intervention in the most rural and remote districts of Zambia: a process evaluation of safe motherhood action groups. Implement Sci. 2018;13(1):74.

6. Jennings MC, Pradhan S, Schleiff M, Sacks E, Freeman PA, Gupta S, et al. Comprehensive review of the evidence regarding the effectiveness of community-based primary health care in improving maternal, neonatal and child health: 2 . maternal health findings. J Glob Health. 2017;7(1):010902.

7. Nyamtema AS, Urassa DP, van Roosmalen J. Maternal health interventions in resource limited countries: a systematic review of packages, impacts and factors for change. BMC Pregnancy Childbirth. 2011;11:30.

8. Sharma BB, Jones L, Loxton DJ, Booth D, Smith R. Systematic review of community participation interventions to improve maternal health outcomes in rural South Asia. BMC Pregnancy Childbirth. 2018;18(1):327.

9. Sircar NR, Friedman EA. Financial security and public health: how basic income \& cash transfers can promote health. Glob Public Health. 2018;13(12):1878-88.

10. Javanparast S, Windle A, Freeman T, Baum F. Community health worker programs to improve healthcare access and equity: are they only relevant to Low- and Middle-Income Countries? Int J Health Policy Manag. 2018;7(10):943-54.

11. Mehrotra S, Mehrotra V.S. Challenges Beyond Schooling: Innovative Models for Youth Skills Development in India. In: Pavlova M, Lee JK, Maclean R, editors. Transitions to Post-School Life. Education in the Asia-Pacific Region: Issues, Concerns and Prospects. Singapore: Springer; 2018.

12. Santha SD, Banerjee S, Sasidevan D. Mapping Social Innovation Among Youth and Adolescents: A Situational Assessment of Livelihood Promotion and Enhancement Initiatives in India. In: Bharat S, Sethi G, editors. Health and Wellbeing of India's Young People. Singapore: Springer; 2019.

13. Census 2011. Government of India. https://www.census2011.co.in/states.php. Accessed 20 Nov 2019.

14. Niti Ayog and United Nations. SDG India; Index and Dashboard 2019-20. https://niti.gov.in/sites/default/files/201912/SDG-India-Index-2.0_27-Dec.pdf. Accessed 1 Jan 2020.

15. Rajasthan human development report 2002. http://planningcommission.nic.in/plans/stateplan/sdr_pdf/shdr_raj02.pdf. Accessed 7 Nov 2019.

16. Ministry of Women and Child Development; Government of India. Integrated Child Development Service Scheme. https://icds-wcd.nic.in/icds.aspx. Accessed 1 Jan 2020.

Page $13 / 18$ 
17. Ved R, Sheikh K, George AS, Raman VR. Village Health Sanitation and Nutrition Committees: reflections on strengthening community health governance at scale in India. BMJ Glob Health. 2018;3:e000681.

18. Mozumdar A, Khan ME, Mondal SK, Mohanan PS. Increasing knowledge of home based maternal and newborn care using self-help groups: Evidence from rural Uttar Pradesh, India. Sex Reprod Healthc. 2018;18:1-9.

19. Lyngdoh T, Neogi SB, Ahmad D, Soundararajan S, Mavalankar D. Intensity of contact with frontline workers and its influence on maternal and newborn health behaviors: cross-sectional survey in rural Uttar Pradesh, India. J Health Popul Nutr. 2018;37(1):2.

20. George AS, Mohan D, Gupta J, LeFevre AE, Balakrishnan S, Ved R, et al. Can community action improve equity for maternal health and how does it do so? Research findings from Gujarat, India. Int J Equity Health. 2018;17(1):125.

21. Saggurti N, Porwal A, Atmavilas Y, Walia M, Das R, Irani L. Effect of behavioral change intervention around new-born care practices among most marginalized women in self-help groups in rural India: analyses of three cross-sectional surveys between 2013 and 2016. J Perinatol. 2019;39:990-9.

22. Saggurti N, Atmavilas Y, Porwal A, Schooley J, Das R, Kande N, et al. Effect of health intervention integration within women's self-help groups on collectivization and healthy practices around reproductive, maternal, neonatal and child health in rural India. PLoS ONE. 2018;13(8):e0202562.

23. United Nations Children's Fund. Ending Child Marriage: A profile of child marriage in India. 2019. https://data.unicef.org/wp-content/uploads/2019/02/Child-Marriage_India_for-digital_0215.pdf. Accessed 15 Dec 2019.

24. Government of India. Pradhan Mantri Kaushal Vikas Yojna. http://pmkvyofficial.org/Dashboard.aspx. Accessed 18 Dec 2019.

25. Raj M. Pradhan Mantri Kaushal Vikas Vojana: Challenges and opportunities. Int J Acad Res Dev. 2018;3(1):486-9.

26. Sharma G, Penn-Kekana L, Halder K, Filippi V. An investigation into mistreatment of women during labour and childbirth in maternity care facilities in Uttar Pradesh, India: a mixed methods study. Reprod Health. 2019; doi:10.1186/s12978-0190668-y.

27. Lorthios-Guilledroit A, Richard L, Filiatrault J. Factors associated with the implementation of community-based peer-led health promotion programs: a scoping review. Eval Program Plann. 2018;68:19-33.

28. Sun WH, Miu HYH, Wong CKH, Tucker JD, Wong WCW. Assessing participation and effectiveness of the peer-led approach in youth sexual health education: Systematic Review and Meta-Analysis in more developed countries. J Sex Res. 2018;55(1):31-44.

29. Mahat G, Scoloveno MA. Effectiveness of adolescent peer education programs on reducing HIV/STI risk: an integrated review. Res Theory Nurs Pract. 2018;32(2):168-98.

30. Government of Rajasthan and Department of Rural Development and Panchayati Raj. 2010. Rajasthan rural livelihood project.

http://documents.worldbank.org/curated/en/304151468267326628/pdf/IPP4550REVISED1blic10BOX353791B1pdf.pdf. Accessed 1 Dec 2019.

\section{Tables}

\section{Table 1. The logic model of the intervention}




\begin{tabular}{|c|c|c|c|}
\hline Objective & Strategies & & Output \\
\hline \multirow[t]{2}{*}{$\begin{array}{l}\text { Improve KAP of marginalized } \\
\text { communities for improving MNCH } \\
\text { through life course approach }\end{array}$} & Women & $\begin{array}{l}\text { 1.Groups formation } \\
\text { (25-30 per group) } \\
\text { 2.Four days' } \\
\text { induction training } \\
\text { 3.Two days' } \\
\text { refresher training } \\
\text { three times } \\
\begin{array}{l}\text { 4.Peer-led education } \\
\text { sessions } \\
\text { beneficiaries for }\end{array}\end{array}$ & $\begin{array}{l}\text { 1.Perceived } \\
\text { improvement in KAP } \\
\text { on MNCH services } \\
\text { 2.Perceived in } \\
\text { improvement and } \\
\text { accessibility atilization of services. } \\
\text { utilis }\end{array}$ \\
\hline & Adolescents & $\begin{array}{l}\text { 1.Establishment of } \\
\text { YIC } \\
\text { 2.Community } \\
\text { mobilization for } \\
\text { accessing services } \\
\text { 3.Integrated } \\
\text { education package } \\
\text { on SRHR } \\
\text { 4.Induction \& } \\
\text { refresher training of } \\
\text { peer leaders and } \\
\text { education sessions } \\
\text { conducted by them in } \\
\text { community } \\
\text { 5.Infotainment } \\
\text { sessions at } \\
\text { YIC/Schools }\end{array}$ & $\begin{array}{l}\text { 1.Perceived } \\
\text { improvement in KAP } \\
\text { on SRHR issues and } \\
\text { services } \\
\text { 2. } \\
\text { increment in school } \\
\text { retention } \\
\text { 3. Perceived reduction } \\
\text { in the incidence of } \\
\text { early marriage. }\end{array}$ \\
\hline $\begin{array}{l}\text { Establish linkages and } \\
\text { enabling envireate } \\
\text { accessibility and utilization of } \\
\text { health services }\end{array}$ & $\begin{array}{lr}\text { Family members } \\
\text { including parents, in- } \\
\text { laws, husbands, } \\
\text { community } \\
\text { gatekeepers } \\
\text { including } \\
\text { members }\end{array}$ & $\begin{array}{l}\text { 1. Community } \\
\text { mobilization and } \\
\text { empowerment } \\
\text { 2. Networking and } \\
\text { strengthening } \\
\text { community-based } \\
\text { institutions } \\
\text { 3.Joints meetings } \\
\text { with relevant } \\
\text { stakeholders } \\
\text { 4.Community folk } \\
\text { activities lie fol magician } \\
\text { dance, and role } \\
\text { shows, and plays. } \\
\text { 5.Linking } \\
\text { beneficiaries with the } \\
\text { Govt. schemes }\end{array}$ & $\begin{array}{l}\text { 1.Perceived increase } \\
\text { in health seeking } \\
\text { behavior on MNCH \& } \\
\text { SRHR issues of } \\
\text { women and } \\
\text { adolescents } \\
\text { 2. Perceived increase } \\
\text { in knowledge of } \\
\text { frontline workers, } \\
\text { community } \\
\text { stakeholders on issues } \\
\text { of MNCH+SRHR }\end{array}$ \\
\hline $\begin{array}{l}\text { Promote financial literacy and } \\
\text { livelihood training program among } \\
\text { identified young people (15-19 } \\
\text { years) for improving } \\
\text { livelihood/employment } \\
\text { opportunities and linkages }\end{array}$ & $\begin{array}{l}\text { Young people } 15-29 \\
\text { years }\end{array}$ & $\begin{array}{l}\text { 1.Selection of young } \\
\text { people } \\
\text { 2.Conduct training } \\
\text { on livelihood skills } \\
\text { and financial } \\
\text { planning }\end{array}$ & $\begin{array}{l}\text { 1.Perceived increase } \\
\text { in livelihood } \\
\text { opportunities in the } \\
\text { communities }\end{array}$ \\
\hline
\end{tabular}


Abbreviations: KAP: Knowledge, Attitude and Practices; MNCH: Maternal, Newborn, and Child Health; SRHR; Sexual and Reproductive Health Rights; VHSNC: Village Health Sanitation and Nutrition Committee; YIC: Youth Information Center

Table 2. Distribution of the socio-demographic details of adolescent peer leaders

\begin{tabular}{|l|l|}
\hline Variables & $\begin{array}{l}\text { Nagaur and Pali (n=977) } \\
\mathrm{N}(\%)\end{array}$ \\
\hline Age (years) & $526(54.0)$ \\
$10-14$ & $451(46.0)$ \\
\hline $\begin{array}{l}\text { Gender } \\
\text { Boys }\end{array}$ & $468(47.9)$ \\
Girls & $509(52.1)$ \\
\hline Religion & $879(90.0)$ \\
Hindu & $98(10.0)$ \\
Muslim & $154(15.8)$ \\
\hline Caste & $10(1.0)$ \\
Scheduled caste & $733(75.0)$ \\
Scheduled tribe & $80(8.2)$ \\
Other backward class \\
General
\end{tabular}

Table 3. District-wise distribution of the descriptive data of adolescents engaged in the intervention 


\begin{tabular}{|l|l|l|}
\hline Variables & $\begin{array}{l}\text { Nagaur (n=4249) } \\
\text { N(\%) }\end{array}$ & $\begin{array}{l}\text { Pali (n=3909) } \\
\text { N(\%) }\end{array}$ \\
\hline Age (years) & $1985(46.7)$ & $1639(41.9)$ \\
$10-14$ & $2264(53.3)$ & $2270(58.1)$ \\
$15-19$ & $2125(50.0)$ & $1857(47.5)$ \\
\hline Gender & $2124(50.0)$ & $2052(52.5)$ \\
Boys & $3959(93.2)$ & $3852(98.5)$ \\
Girls & $290(6.8)$ & $57(1.5)$ \\
\hline Religion & & \\
Hindu & $580(13.7)$ & $499(12.8)$ \\
Muslim & $887(20.9)$ & $1677(42.9)$ \\
\hline Caste & $2782(65.5)$ & $1733(44.3)$ \\
General & $1317(31.0)$ & $1467(37.5)$ \\
Scheduled caste & $731(17.2)$ & $2018(51.6)$ \\
Other marginalized class & $424(10.8)$ \\
\hline Education sessions attended & Never attended any session & \\
Attended <50\% sessions & $1401(51.8)$ & \\
Attended >50\% sessions & $2250(21.70$ \\
\hline Education status & $1484(34.9)$ & $1593(40.8)$ \\
Up to middle school & $1833(43.1)$ & $1466(37.5)$ \\
High school & $932(21.9)$ & \\
Senior secondary school &
\end{tabular}

Table 4. District-wise distribution of the descriptive data of the women engaged in the intervention

\begin{tabular}{|l|l|l|}
\hline Variables & Nagaur $(\mathrm{n}=3310)$ & Pali $(\mathrm{n}=1543)$ \\
\hline Age (years) & $321(9.7)$ & $107(7.0)$ \\
$15-20$ & $1809(54.7)$ & $864(56.0)$ \\
$21-25$ & $1041(31.5)$ & $499(32.3)$ \\
$26-30$ & $139(4.2)$ & $73(4.7)$ \\
$>30$ & $250(7.6)$ & $119(7.7)$ \\
\hline Early marriage (<18 years) & $3060(92.4)$ & $1424(92.7)$ \\
Yes & $3191(96.4)$ & $1517(98.3)$ \\
No & $119(3.6)$ & $26(1.7)$ \\
\hline Religion & $506(15.3)$ & $205(13.3)$ \\
Hindu & $914(27.6)$ & $433(28.0)$ \\
Muslim & $307(9.3)$ & $304(19.7)$ \\
\hline Social class & $1583(47.8)$ & $601(39.0)$ \\
General & & \\
Scheduled caste & & \\
Scheduled tribe & & \\
Other backward classes & $1813(54.8)$ & $765(49.6)$ \\
\hline Category of the beneficiary at the time of enrollment in project & & $778(50.4)$ \\
\hline Pregnant women & $1497(45.2)$ & \\
Lactating mothers & $1164(35.2)$ & $433(28.0)$ \\
& $1134(34.3)$ & $556(36.0)$ \\
\hline Education sessions attended & $1012(30.6)$ & $554(36.0)$ \\
\hline Never & & \\
\hline <0\% of sessions attended & & \\
\hline 50\% of sessions attended & & \\
\hline
\end{tabular}


Supplementary Table S1. District-wise distribution of the maternal, child, and adolescent health indicators

\begin{tabular}{|c|c|c|}
\hline Indicators* & $\begin{array}{l}\text { Nagaur (Ladnun) } \\
\%\end{array}$ & $\begin{array}{l}\text { Pali (Rani) } \\
\%\end{array}$ \\
\hline \multicolumn{3}{|l|}{ Pregnancy Care } \\
\hline$\%$ of women who received at least 3 ANC check up & 46.7 & 62.3 \\
\hline Mothers who received at least one Tetanus Toxoid (TT) injection (\%) & 92.2 & 88.7 \\
\hline$\%$ of mothers who consumed IFA for 100 days or more & 5 & 12.7 \\
\hline \multicolumn{3}{|l|}{ Postpartum care } \\
\hline$\%$ of institutional deliveries & 83.4 & 72.8 \\
\hline \% of women using any methods for family planning & 68.5 & 62.2 \\
\hline \multicolumn{3}{|l|}{ New born } \\
\hline$\%$ of children received breast fed within 1 hour of delivery & 76.6 & 55.6 \\
\hline \% of children exclusively breastfed for 6 months & 27.1 & 50.1 \\
\hline \multicolumn{3}{|l|}{ Child care } \\
\hline $\begin{array}{l}\text { \% of children age } 6-2 \text { years months receiving solid or semi-solid food and } \\
\text { breast milk }\end{array}$ & 4 & 9.4 \\
\hline \% of children fully immunized & 91.4 & 74.2 \\
\hline \multicolumn{3}{|l|}{ Adolescent } \\
\hline Marriages among Females below 18 years & 15.4 & 17.3 \\
\hline Marriages among Males below legal age (21 years) (\%) & 32.2 & 27.7 \\
\hline
\end{tabular}

Abbreviations: ANC: Antenatal Checkups; IFA: Iron Folic Acid tablets

*Source: Annual Health Survey-Rajasthan 2012-2013

\section{Figures}

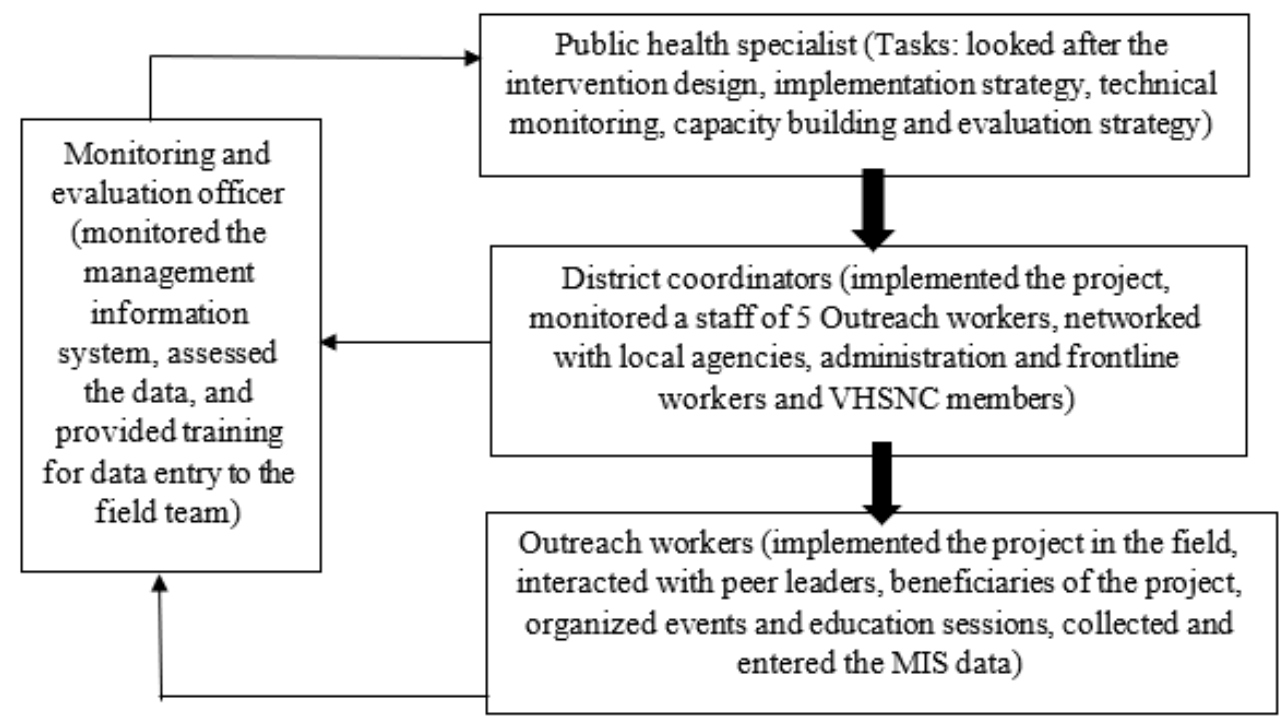

Figure 1

Roles of the implementation actors of the project Abbreviations: VHSNC: Village Health Sanitation and Nutrition Committee; MIS: Management Information System 